\title{
Prurigo nodular crónico
}

\section{Chronic nodular prurigo}

Carla Esteves ${ }^{1}$, María Sylviée ${ }^{2}$ Sandra García ${ }^{3}$, Martina Vannelli ${ }^{4}$ Ítalo Aloise ${ }^{5}$

\section{RESUMEN}

El prurigo nodular crónico se caracteriza por un ciclo de prurito y excoriación en el que intervienen mecanismos neurodérmicos, asociado a diversas enfermedades. Se manifiesta con placas o nódulos hiperqueratósicos cupuliformes. El tratamiento, enfocado en reducir el prurito, representa un desafío por la frecuente resistencia a las terapéuticas habituales.
Se describe el caso de un hombre de 72 años, con antecedentes psiquiátricos, que presentó una dermatosis pruriginosa recalcitrante refractaria a múltiples esquemas de tratamiento.

Palabras clave: prurigo nodular, prurito.

Dermatol. Argent. 2021, 27 (2): 69-71

\section{ABSTRACT}

Chronic prurigo nodularis is characterized by a cycle of itching and excoriation involving neurodermal mechanisms, associated with various diseases. It manifests with cupuliform hyperkeratotic plaques or nodules. Treatment is focused on reducing itching and is a challengue due to the frequent resistance to the usual therapies.
We present the case of a 72-year-old man with a psychiatric history, who presented a recalcitrant pruritic dermatosis refractory to multiple treatment regimens.

Key words: nodular prurigo, pruritus.

Dermatol. Argent. 2021, 27 (2):69-71
${ }^{1}$ Médica Residente

2 Médica de Planta

${ }^{3}$ Dermopatóloga, Servicio de Anatomía Patológica

4 Jefa de Residentes

${ }^{5}$ Jefe del Servicio

Servicio de Dermatología, Hospital de Trauma y Emergencia Dr. Federico Abete, Malvinas Argentinas, Provincia de Buenos Aires, Argentina
Contacto de la autora: Carla Esteves

E-mail: carlaesteves89@hotmail.com Fecha de trabajo recibido: 14/1/2021

Fecha de trabajo aceptado: 3/6/202

Conflicto de interés: los autores declaran que no existe conflicto de interés.

\section{CASO CLÍNICO}

Un paciente de 72 ańos, con antecedentes de trastorno de ansiedad generalizada, medicado con sertralina y carbamazepina, consultó por una dermatosis asociada a un prurito intenso en los miembros, de un año de evolución. En el examen físico presentaba xerosis generalizada y pequeñas placas hiperqueratósicas de centro blanquecino y borde hiperpigmentado, excoriadas, en los miembros superiores e inferiores (Fotos 1 y 2). La impresión diagnóstica inicial fue la de un prurigo nodular, por lo que se realizaron estudios complementarios para confirmarla. 
Los resultados del laboratorio evidenciaron, como datos positivos, hematocrito de $35 \%$, eosinofilia de $15 \%$ y eritrosedimentación de $27 \mathrm{~mm} /$ hora. El resto de los valores estaban dentro de los parámetros de la

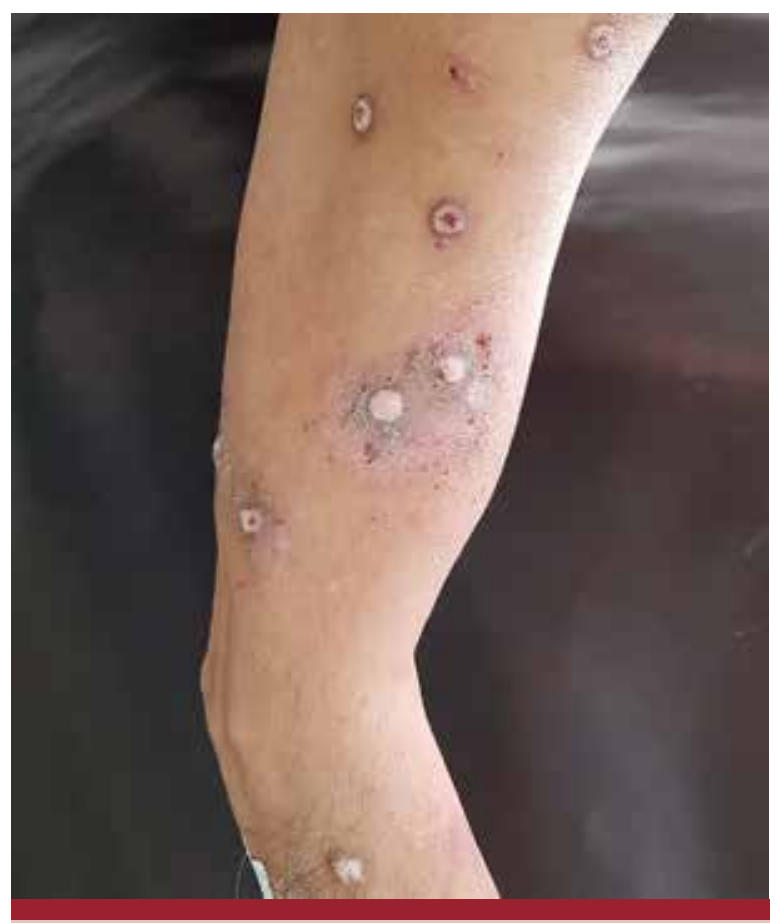

F0T0 1: Pequeñas placas hiperqueratósicas con un borde hiperpigmentado en el miembro superior derecho.

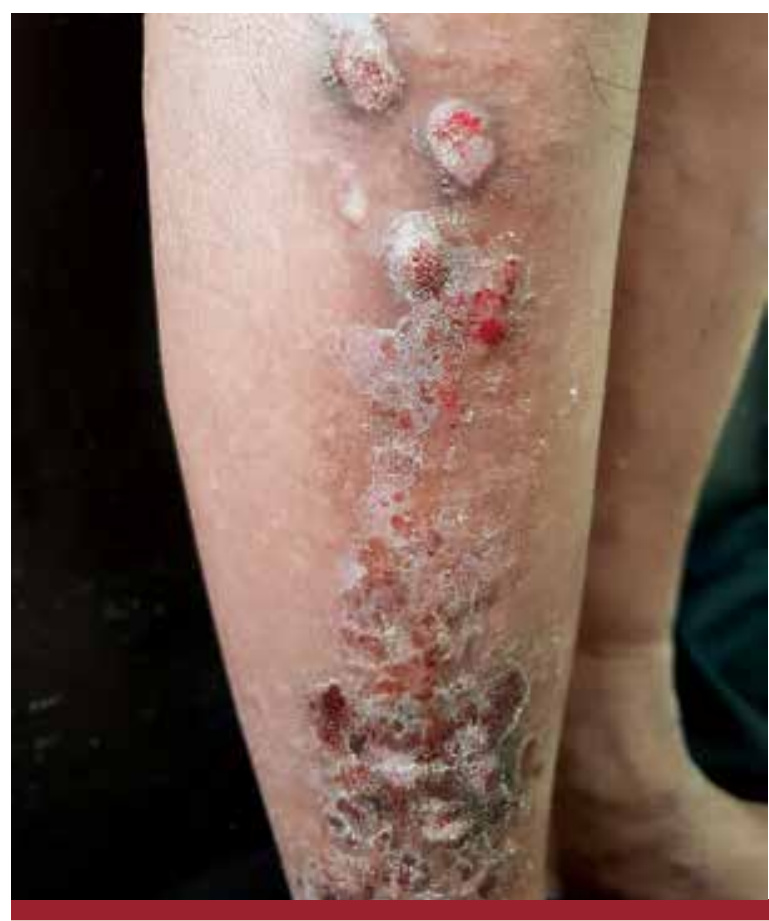

FOTO 2: Placas liquenificadas con un centro blanquecino, excoriadas, en el miembro inferior derecho. normalidad. El estudio histopatológico informó: hiperparaqueratosis y acantopapilomatosis (Foto 3); focos de paraqueratosis con glóbulos de fibrina debidos a un rascado intenso, hallazgos vinculables al prurigo nodular (Foto 4).

Se evaluó la gravedad y extensión según la escala Investigator Global Assessment (IGA) y se lo clasificó en grado III moderado (ya que presentaba 32 lesiones cutáneas).

Se le indicó cetirizina $20 \mathrm{mg} /$ día, pregabalina 75 $\mathrm{mg} /$ día y clobetasol tópico. Por la escasa respuesta, a los 2 meses se rotó a talidomida $100 \mathrm{mg} /$ día y, por el agravamiento del cuadro, a los 3 meses se decidió iniciar tratamiento con dupilumab. Sin embargo, antes de comenzarlo, el paciente falleció por una causa no relacionada con su enfermedad dermatológica.
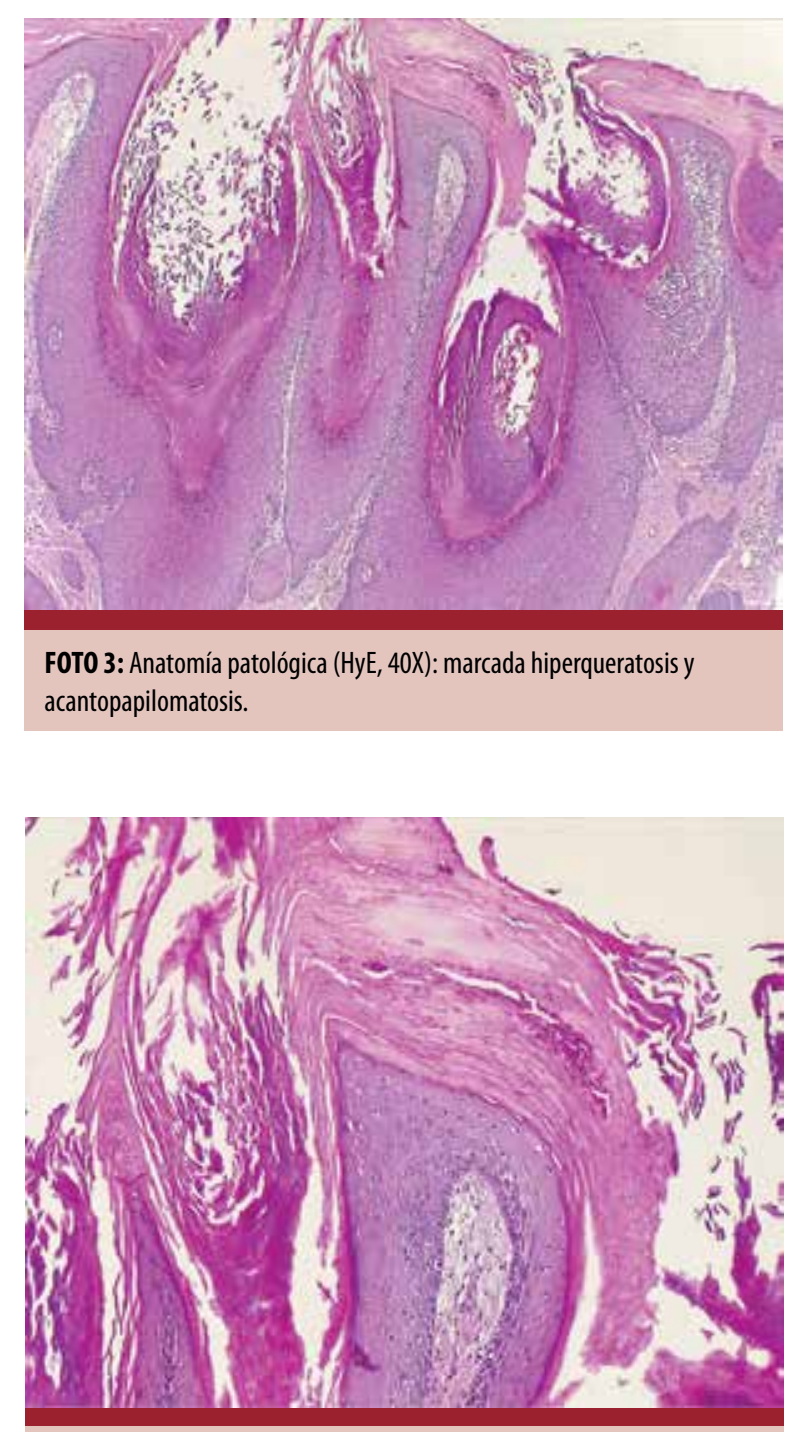

F0T0 4: Anatomía patológica (HyE, 100X): focos de paraqueratosis que circundan glóbulos de fibrina debido al rascado intenso. 


\section{COMENTARIOS}

El prurigo nodular (PN) forma parte de los prurigos crónicos. Es una neurodermitis crónica caracterizada por un ciclo de prurito-rascado que tiene un alto impacto en la calidad de vida, con predilección por los adultos de mediana edad y los afroamericanos ${ }^{1-3}$.

Su etiología es poco conocida y se asocia a múltiples trastornos, como dermatitis atópica, diabetes mellitus tipo 2, trastornos tiroideos, infección por el virus de la hepatitis $\mathrm{C}$, linfoma no Hodgkin, depresión mayor y ansiedad, como presentaba el paciente ${ }^{1,2,4}$.

La patogenia está en investigación. Algunos estudios mostraron que existe una relación entre los factores neuropáticos y los inflamatorios. Se evidenció hiperplasia e hipertrofia de fibras nerviosas dérmicas, hipoplasia de fibras nerviosas intraepidérmicas y alteraciones de los neuropéptidos o las neurotrofinas, que inducen la expresión de histamina, y aumento de las interleuquinas (IL) 31, 6, 4, 13 y de la serotonina ${ }^{1,3-5}$.

Clínicamente, presenta nódulos y placas cupuliformes, hiperqueratósicos y excoriados, con un centro blanquecino o rosado y un borde hiperpigmentado, de 2 a 3 $\mathrm{cm}$, como se evidencia en las fotos 1 y 2 correspondientes al paciente. La distribución, simétrica en los miembros y el tronco, respeta el dorso superior y las zonas facial y palmoplantar. El prurito es incoercible y repercute en alto grado en la calidad de vida del paciente $e^{1,3-7}$.

La histopatología a nivel epidérmico presenta ortoqueratosis gruesa, hiperplasia epidérmica irregular e hipergranulosis focal o amplia. En la dermis papilar, se evidencia fibrosis con disposición vertical de fibras de colágeno, aumento de los fibroblastos y los capilares, e infiltrado inflamatorio compuesto por linfocitos e his-

\section{BIBLIOGRAFÍA}

1. Serra-García L, Morgado-Carrasco D. Prurigo nodular. Piel (Barc). 2020;35:563-576.

2. Fostini A, Girolomoni G, Tessari G. Prurigo nodularis: an update on etiopathogenesis and therapy. J Dermatolog Treat, 2013;24:458-462.

3. Kowalski E, Kneiber D, Valdebran M, Patel U, et ál. Treatmentresistant prurigo nodularis: challenges and solutions. Clin Cosmet Investig Dermatol 2019;12:163-172.

4. Carreras C, Aguirre G, Rayan M, Palmeyro C, et ál. Dermatosis provocadas por desórdenes psiquiátricos. Estudio retrospectivo de 48 pacientes. Dermatol Argent. 2013;19:194-197.

5. Giura MT, Viola R, Fierro M, Ribero $S$, et ál. Efficacy of dupilumab in prurigonodularis in elderly patient. Dermatol Ther 2020;33:1-3.

6. Kwon C, Khanna R, Williams K, et ál. Diagnostic workup and tiocitos. Las unidades foliculosebáceas muestran una capa cornificada, gruesa y compacta ${ }^{3,6}$.

Los estudios complementarios se solicitan para la búsqueda de patologías asociadas. Se debe pedir un laboratorio completo que incluya perfil tiroideo, pruebas serológicas para VHC, VHB, VIH y VDRL, estudios imagenológicos y biopsia cutánea ${ }^{6,7}$.

No se cuenta con un tratamiento específico. Las opciones terapéuticas incluyen corticosteroides; inhibidores de la calcineurina tópicos y emolientes; antihistamínicos; gabapentinoides; antidepresivos; antagonistas opioides, e inmunosupresores como ciclosporina, azatioprina, metotrexato y talidomida. También hay estudios con fototerapia ultravioleta y láser de excímero ${ }^{1,3,7}$.

El dupilumab se presenta como una nueva y efectiva alternativa de tratamiento. Es un anticuerpo monoclonal disponible en Argentina, actúa como antagonista del receptor de IL-4 que inhibe la señalización de IL-4 e IL-13, lo cual genera reducción del prurito, disminución de las lesiones y mejora de la calidad de vida. La dosis inicial es $600 \mathrm{mg}$ por vía subcutánea, seguida de $300 \mathrm{mg}$ cada 2 semanas; tiene la ventaja de ser bien tolerado y seguro ${ }^{1,5,7,8}$. Otras terapias en estudio son el aprepitant, el nemolizumab y el serlopitant, que se indicarían para casos resistentes ${ }^{9,10}$.

En el paciente del caso analizado, consideramos que el dupilumab hubiera sido una buena opción terapéutica, dada la escasa respuesta a los tratamientos instaurados. Sostenemos la búsqueda de alternativas y el tratamiento multidisciplinario para aliviar los síntomas del paciente y mejorar así su calidad de vida.

evaluation of patients with prurigo nodularis. Medicines 2019;6:97.

7. Ständer HF, Elmariah S, Zeidler C, Spellman M, et ál. Diagnostic and treatment algorithm for chronic nodular prurigo. J Am Acad Dermatol 2020;82:460-468.

8. Grønlund J, Agner T, Sand C, Thomsen S. Dupilumab for prurigo nodularis: Case series and review of the literature. Dermatol Ther. 2020;33:e13222.

9. Ständer S, Kwon P, Hirman J, Perlman AJ, et ál. Serlopitant reduced pruritus in patients with prurigo nodularis in a phase 2, randomized, placebo-controlled trial. J Am Acad Dermatol. 2019;80:1395-1402.

10. Ständer S, Yosipovitch G, Legat F, Lacour JP, et ál. Trial of Nemolizumab in moderate-to-severe prurigo nodularis. $N$ Engl J Med. 2020;382:706-716. 